\title{
Manejo de vía aérea en paciente con leontiasis ossea. Reporte de caso
}

\author{
Airway management in a patient with leontiasis ossea. Case report \\ Vanessa Vásquez S. ${ }^{1, *}$, Ximena Oliveros H. ${ }^{2}$, Florence Gazabatt S. ${ }^{1}$ \\ Especialista en Anestesiología y Reanimación, Clínica Dávila. Santiago, Chile. \\ 2 Residente de Primer Año de Anestesiología y Reanimación, Universidad de los Andes. Santiago, Chile.
}

Fecha de recepción: 07 de enero de 2021 / Fecha de aceptación: 18 de marzo de 2021

\begin{abstract}
Leontiasis ossea is an uncommon complication of advanced chronic kidney disease that alters the facial bone and the airway, making its perioperative management more complex. We present a clinical case of a female with Leontiasis ossea presenting a difficult airway which requires parathyroidectomy. Assessment, planning and management of the airway by awake intubation is described.
\end{abstract}

Key words: Leontiasis ossea, difficult airway, renal osteodystrophy.

\section{RESUMEN}

La leontiasis ossea es una complicación infrecuente de la enfermedad renal crónica avanzada que altera el macizo facial óseo y la vía aérea, complejizando su manejo perioperatorio. Presentamos caso clínico de mujer portadora de leontiasis ossea con vía aérea difícil requiriendo paratiroidectomía. Se describe valoración, planificación y manejo de vía aérea mediante intubación vigil.

Palabras clave: Leontiasis ossea, vía aérea difícil, osteodistrofia renal.

\section{Introducción}

eontiasis Ossea (LO) es el término clínico que describe un sobrecrecimiento del macizo facial resultante en apariencia felina. Infrecuente, su principal etiología es la osteodistrofia renal (OR) en pacientes con enfermedad renal crónica (ERC) avanzada e hiperparatiroidismo secundario (HPS)[1]. Su tratamiento, en contexto de OR, incluye manejo médico del HPS, paratiroidectomía e incluso osteoplastía[2]. Además, de sus implicancias estéticas y de la comorbilidad propia de la ERC, la LO altera significativamente la vía aérea planteando desafíos durante el perioperatorio de los pacientes portadores[3],[4],[5]. Los algoritmos de manejo de vía aérea orientan al abordaje vigil en pacientes con vía aérea difícil (VAD) anticipada[6]. La intubación (IET) con fibrobroncoscopía flexible (FBCF) es una opción de manejo vigil que requiere habilidades técnicas, colaboración del paciente y adecuada preparación[7]. Presentamos a conti- nuación caso clínico de paciente con LO, agendada para paratiroidectomía, donde se utilizó IET/FBCF como abordaje.

\section{Caso clínico}

Paciente femenina, de 39 años de edad, hipertensa, con ERC terminal secundaria a síndrome hipertensivo del embarazo, 10 años en hemodiálisis y con indicación de paratiroidectomía por HPS. Asiste a valoración ambulatoria preanestésica donde se evidencia importante deformidad en rostro con aumento de volumen facial, crecimiento mandibular y maxilar, elevación de piso de boca, aplanamiento de nariz, dientes separados, lengua rechazada a posterior con protrusión limitada y Mallampati IV (Figura 1). A la anamnesis dirigida paciente refiere inicio paulatino de alteraciones descritas hace 1 año, desarrollando también rinolalia progresivamente. Sin consulta previa por altera- 


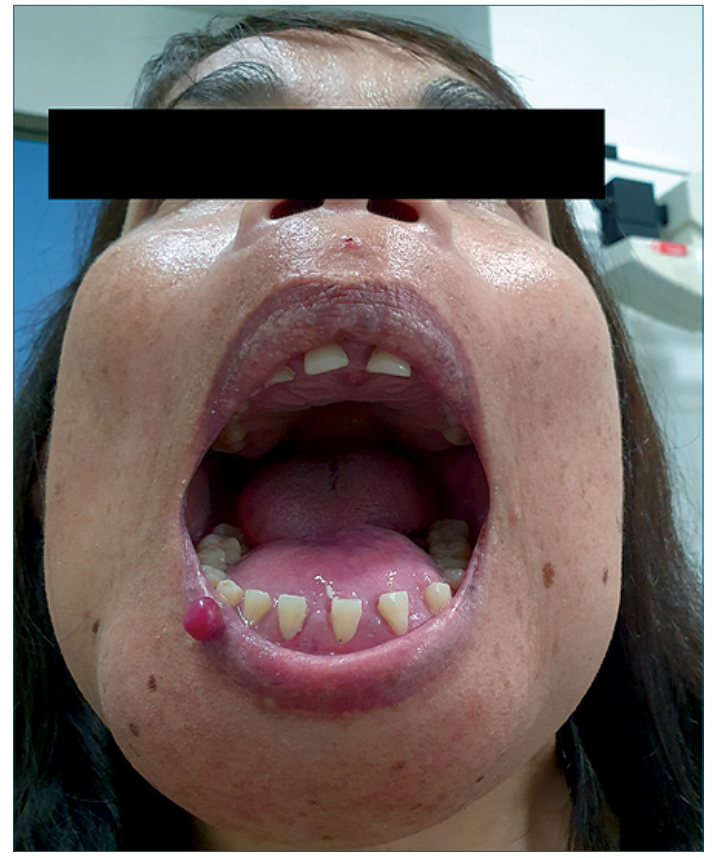

Figura 1. Mallampati de la paciente. ción. Se decide, junto a cirujano tratante, estudio con imágenes y se solicita TC maxilofacial que informa: "extensa alteración de estructura ósea de bóveda craneana, base de cráneo y macizo facial, extenso ensanchamiento mandibular y maxilar con imágenes tuneliformes. Compromete todo el macizo facial sin masa de partes blandas. Separación aumentada de piezas dentarias y menor amplitud de cavidad oral. Hallazgos compatibles con leontiasis urémica (Figura 2).

Se decide continuar con paratiroidectomía, discutiéndose abordaje de vía aérea con servicio de anestesia y tratante. Se define abordaje vigil con IET/FBCF vía nasal como primer intento, vía oral como segundo intento y de fallar traqueostomía vigil.

Dos anestesiólogos participaron en el procedimiento: uno encargado de los medicamentos y otro de la vía aérea. Tras realizar monitorización estándar se administró lidocaína spray al $10 \%$ a pared posterior de orofaringe, solicitando a paciente hacer gárgaras y mantener solución el mayor tiempo posible, rociando ambas fosas nasales también. Gasas con solución de lidocaína al $1 \%$ fueron instaladas en bases de arcos palatoglosos y se insertó tórula con igual solución, profunda en fosa nasal izquierda, buscando anestesia tópica. Se marcó membrana cricotiroidea utilizando ecografía.
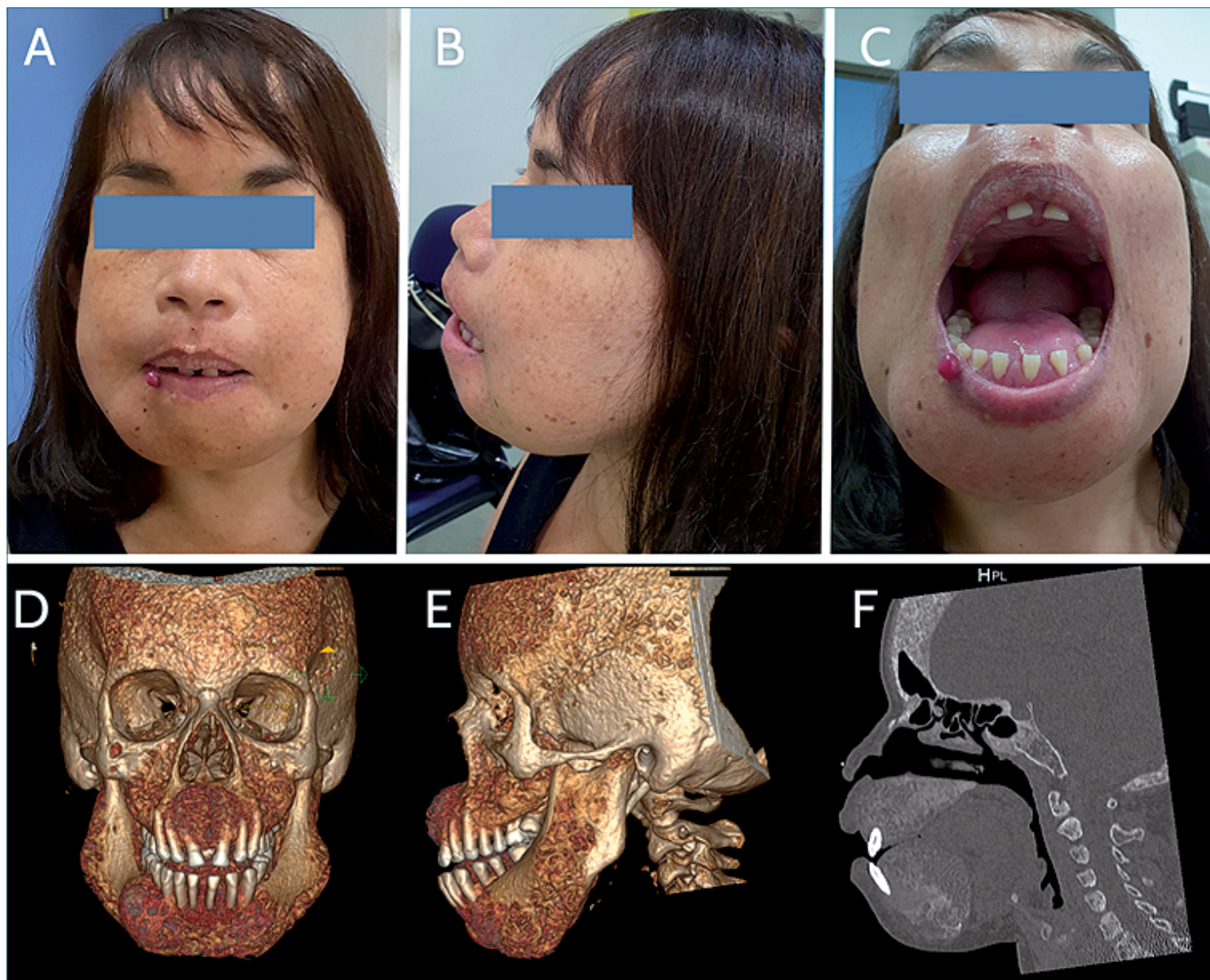

Figura 2. Apariencia física y estudio imagenológico de paciente. Las imágenes $A, B$ y $C$ muestran visión frontal, lateral y apertura bucal al examen físico, respectivamente. En la fila inferior, D y E corresponden a reconstrucción 3D de TC maxilofacial donde se evidencia sobrecrecimiento óseo. F muestra corte sagital de TC en que se aprecia rechazo hacia posterior de lengua por crecimiento mandibular y aspecto tunelizado de hueso anómalo. 
Con paciente semisentada se realizó preoxigenación con máscara facial, dejando luego naricera a $3 \mathrm{l} / \mathrm{min}$. Se inició bomba de infusión controlada por objetivo $(\mathrm{TCl})$ de remifentanilo utilizando modelo Minto, con objetivo sitio efecto inicial 1 $\mathrm{ng} \cdot \mathrm{ml}^{-1}$ aumentándose gradualmente hasta $3 \mathrm{ng} \cdot \mathrm{ml}^{-1}$. Bomba de $\mathrm{TCl}$ fue programada utilizando peso seco habitual de diálisis. Paciente mantuvo vigilia, ventilando adecuadamente y obedeciendo órdenes. El anestesiólogo encargado de la vía aérea se situó frente a la paciente y realizó FBCF $\left(\mathrm{Ambu}^{\circledR} \mathrm{aScope}^{\mathrm{TM}}\right.$ sonda regular 5,0/2,2) con TET número 7 enhebrado, ingresando por narina izquierda. Tras 2 intentos infructuosos por tope de sonda, se decidió variar estrategia cambiando posición de paciente a decúbito supino y reubicándose el anestesiólogo operador de vía aérea hacia posterior de la cabecera de la paciente, sobre escabel y con mesa quirúrgica a mínima altura, intentando esta vez acceso oral. Se mantuvo comunicación con paciente constantemente. Se ingresó fibrobroncoscopio hasta localizar glotis y luego hasta carina, deslizando TET. Paciente presentó tos al atravesar la glotis manteniendo saturación de $98 \%$ y estabilidad hemodinámica durante procedimiento, basalmente hipertensa. Posicionado el TET se retiró el fibrobroncoscopio y conectó circuito de anestesia, se infló cuff y corroboró capnografía. Se administraron $150 \mathrm{mg}$ de propofol y $50 \mathrm{mg}$ de rocuronio ev, continuándose infusión de propofol con modelo Marsh. Se mantuvo remifentanilo. Tras inducción se corroboró con fibrobroncoscopio posición del TET, quedando punta a 5 $\mathrm{cm}$ de carina.

La paratiroidectomía duró 2 h. Finalizada la cirugía se monitorizó y revirtió bloqueo neuromuscular con neostigmina 1,5 $\mathrm{mg}$ asociado a atropina 0,5 mg. Se redujo remifentanilo a 0,5 $\mathrm{ng} \cdot \mathrm{ml}^{-1}$ y suspendió propofol. Secreciones fueron aspiradas. Lograda adecuada mecánica ventilatoria y vigilia, se extubó sin incidentes. Paciente fue trasladada a servicio de intermedio quirúrgico donde se realizó hemodiálisis programada y cuidados posoperatorios, evolucionando satisfactoriamente.

\section{Discusión}

La LO es una manifestación infrecuente de la OR[1], por este motivo la literatura sobre su manejo perioperatorio está constituida principalmente por reportes de casos. El nuestro, por su naturaleza electiva, permitió realizar estudio imagenológico y discusión de planes en equipo. Las principales consideraciones fueron la ERC y el manejo de VAD. Sobre el manejo de vía aérea se ha reportado manejo exitoso con fibrobroncoscopía nasal vigil[4] en circunstancias electivas similares a la nuestra. En tanto, situaciones de emergencia han evidenciado dificultad de laringoscopia directa bajo anestesia general, Ilegando a requerirse acceso frontal de cuello de emergencia[5]. Las guías de manejo de vía aérea difícil sugieren un enfrentamiento vigil cuando esta es anticipada[6], enumerando diversas técnicas a elegir según la situación clínica y habilidades del equipo tratante[7]. En nuestro caso, las imágenes mostraban permeabilidad nasal y disminución del tamaño de la cavidad oral, por lo que decidimos realizar abordaje nasal con fibrobroncoscopio como primer intento. No planificamos intentos vigiles con videolaringoscopio, ya que desconocíamos la fragilidad del hueso anómalo y preferimos evitar riesgo de trauma sobre este. Durante la ejecución, al no lograr acceso vía nasal, decidimos optimizar estrategia, como recomiendan las guías[7], cambiando posición (paciente y operador) y probando un acceso oral, con éxito.

Con respecto a la sedación, se sugieren distintos regímenes, siendo los más mencionados: remifentanilo con o sin midazolam y dexmedetomidina[7]. Considerando el contexto de ERC avanzada, se decidió no adicionar midazolam por su eliminación reducida en pacientes con esta enfermedad 8,9 , lo que aumenta el riesgo de sobresedación. Remifentanilo y dexmedetomidina, en tanto, no sufren modificaciones de relevancia clínica en ERC[10],[11],[12],[13],[14]. Por mayor familiaridad y rápida reversión elegimos remifenitanilo.

Afortunadamente, nuestro intento de IET/FBCF fue exitoso, sin embargo, contábamos con otros planes en caso de fallar, sociabilizados al equipo, lo que respalda la seguridad del paciente.

\section{Conclusiones}

La ERC terminal se asocia a morbilidad importante complejizando manejo de los pacientes portadores, quienes pueden requerir cirugía electiva o de urgencia. La OR es una de sus manifestaciones siendo la LO una complicación poco frecuente, pero desafiante. El manejo de la vía aérea de estos pacientes requiere valoración, planificación, habilidades técnicas y no técnicas. Mantener entrenamiento constante y contar con guías sociabilizadas al equipo de atención es fundamental para resultados exitosos.

\section{Referencias}

1. Fatahzadeh $\mathrm{M}$. The spectrum of orofacial manifestations in renal osteodystrophy: diagnostic challenges of an uncommon presentation. Quintessence Int. 2011 Jul-Aug;42(7):e78-88. PMID:21716979

2. Junior LC, de França GM, Dantas WR, Germano AR. Surgical osteoplasty and soft tissue excision as treatment for facial deformities in patients with renal osteodystrophy: three case reports. Oral Maxillofac Surg. 2020 Jun;24(2):221-7. https://doi.org/10.1007/ s10006-019-00819-5 PMID:31832899

3. Chen Q, Lorenzo J, Lu A. Perioperative Care and Airway Management for a Patient With Sagliker Syndrome. Cureus. 2020 Sep;12(9):e10691. https://doi.org/10.7759/cureus.10691 PMID:33133856

4. Dentz ME, Lubarsky DA. Leontiasis ossea: an unusual presentation of a difficult airway. Anesth Analg. 1993 Mar;76(3):678-9. https://doi.org/10.1213/00000539-199303000-00068 PMID:8452302

5. Gunarso A, Jalalzadeh M, Lwin L, Villanueva H, Yoo J. Leontiasis Ossea (lion face syndrome): a manifestation of renal osteodystrophy, and a cause of disequilibrium syndrome and upper airway obstruction. Am J Kidney Dis. 2019;73(5):678. https://doi. org/10.1053/j.ajkd.2019.03.141.

6. Apfelbaum JL, Hagberg CA, Caplan RA, Blitt CD, Connis RT, Nickinovich DG, et al.; American Society of Anesthesiologists Task Force on Management of the Difficult Airway. Practice guidelines for management of the difficult airway: an updated report by the American Society of Anesthesiologists 
Task Force on Management of the Difficult Airway. Anesthesiology. 2013 Feb;118(2):251-70. https://doi.org/10.1097/ ALN.0b013e31827773b2 PMID:23364566

7. Ahmad I, El-Boghdadly K, Bhagrath R, Hodzovic I, McNarry AF, Mir F, et al. Difficult Airway Society guidelines for awake tracheal intubation (ATI) in adults. Anaesthesia. 2020
Apr;75(4):509-28. https://doi.org/10.1111/anae.14904 PMID:31729018

8. Driessen JJ, Vree TB, Guelen PJ. The effects of acute changes in renal function on the pharmacokinetics of midazolam during long-term infusion in ICU patients. Acta Anaesthesiol Belg. 1991;42(3):149-55. PMID:1767626 